\title{
SANKSI PIDANA OLEH TINDAK PIDANA MENGEDARKAN SIMPANAN FARMASI KOSMETIKA TANPA IZIN EDAR (STUDI KASUS PUTUSAN PENGADILAN NEGERI DENPASAR NO. PERKARA 491/Pid.Sus/2018/PN DPS)
}

\author{
Rafael Aza Pramesuari, I Nyoman Sujana, Diah Gayatri Sudibya \\ Fakultas Hukum, Universitas Warmadewa, Denpasar, Bali \\ rafael.chaca@yahoo.com
}

\begin{abstract}
Abstrak
Penelitian ini bertujuan untuk mengetahui dan menjelaskan sanksi pidana bagi produsen ataupun penjual kosmetik yang tidak memiliki izin edar ini. Jenis penelitian yang digunakan adalah penelitian hukum normatif dengan menganalisis kasus menggunakan Putusan Pengadilan Negeri Denpasar Nomor Perkara 491/Pid.Sus/2018/PN DPS. Penelitian ini menggunakan pendekatan Perundang-undangan dengan menelaah semua Undang-Undang yang berhubungan dengan kasus ini, konseptual yaitu dengan menggabungkan pendapat para ahli sehingga menjadi argumentasi hukum penulis, dan pendekatan kasus yaitu dengan menggunakan putusan pengadilan. Hasil penelitian menunjukan bahwa harus ada unsur-unsur yang menunjukan bahwa seseorang itu telah melakukan tindak pidana, dan didalam penulisan ini ada 3 (tiga) unsur yang menerangkan bahwa terdakwa melakukan suatu tindak pidana. Pengenaan oleh sanksi tindak pidana menyebarkan simpanan farmasi kosmetika yang tidak memperoleh izin edar sebagaimana diatur dalam Undang-Undang Nomor 36 Tahun 2009 tentang kesehatan ini diatur di dalam pasal 197-201. Dalam hal ini, para Majelis Hakim mempertimbangkan dengan Pasal 197 yaitu hukuman penjara maksimal 10 (Sepuluh) tahun dan denda maksimal 1.000.000.000 (Satu Milyar Rupiah). Tetapi, terdakwa disini tak perlu menjalani pidana tersebut kecuali nantinya ada perintah lain dari putusan Hakim telah dipersalahkan melakukan tindak pidana selama masa percobaan belum berakhir.
\end{abstract}

Kata kunci: Sanksi Pidana, Farmasi Kosmetika, Distribusi tanpa Izin

\begin{abstract}
This study aims to identify and explain criminal sanctions for cosmetic producers or sellers who do not have this distribution license. The type of research used is normative legal research by analysing cases using the Denpasar District Court Decision Case Number 491/Pid.Sus 12018/ PN DPS. This study uses a statutory approach by examining all laws related to this case, conceptually by combining the opinions of experts so that it becomes the author's legal argument, and the case approach is by using a court decision. The results of the study show that there must be elements that indicate that a person has committed a criminal act, and in this writing there are 3 (three) elements that explain that the defendant committed a criminal act. Imposition by the criminal sanction of distributing cosmetic pharmaceutical deposits that do not obtain a distribution permit as regulated in Law Number 36 of 2009 concerning health is regulated in articles 197-201. In this case, the Panel of Judges considered Article 197, namely a maximum imprisonment of 10 (ten) years and a maximum fine of 1,000,000,000 (one billion rupiah). However, the defendant here does not need to undergo the sentence unless later there is another order from the Judge's decision that he has been guilty of committing a criminal act during the probation period has not ended.
\end{abstract}

Keywords: Criminal Sanctions, Cosmetics Pharmacy, Distribution without Permit

\section{PENDAHULUAN}

Bersamaan dengan berkembangnya ilmu pengetahuan di Indonesia, mengantarkan masyarakat dalam gaya hidup yang serba praktis. Semakin berkembang peradaban suatu bangsa maka akan semakin maju juga ilmu pengetahuan dalam bangsa tersebut. Jika ilmu pengetahuan yang semakin maju dan tidak dibarengi dengan ilmu kemanusiaan, maka akan menimbulkan dampak yang tidak baik.

Dengan adanya tindak pidana baru di dalam bidang ilmu yang sedang berkembang tersebut menimbulkan gangguan provokasi, ketenangan dan kerap kali mengakibatkan kerugian materil 
maupun immateril bagi masyarakat luas, seperti pada beberapa kasus penelitian yang telah dilakukan oleh DeAngelo \& Gee (2020); Diantara, Widiati, \& Karma (2020); Flores (2016); Lane, dkk., (2020); Peng, Cheng, \& Gong (2021). Ilmu kesehatan merupakan bidang ilmu yang kemajuannya sangat pesat di era ini. Begitu juga dengan kemajuan tindak pidana dibidang ilmu kesehatan. Macam-macam tindak pidana yang terjadi di bidang ilmu kesehatan adalah: malapraktek, pemalsuan obat, pengedaran dan penyalahgunaan obat tanpa izin, transplantasi ilegal organ manusia, dan yang marak terjadi di Indonesia yaitu pengedaran kosmetik tanpa izin edar. Padahal Undang-Undang Dasar Negara Republik Indonesia Tahun 1945 sendiri kesehatan sudah disinggung di dalam pasal 28h ayat (1) yaitu, kesehatan merupakan hak asasi setiap manusia dan merupakan unsur kesejahteraan, maka ini wajib dibangun demi cita-cita bangsa Indonesia sesuai Pancasila dan Undang-Undang Dasar Negara Republik Indonesia Tahun 1945. Selain itu, menurut Ta'adi (2013:5), pengembangan kesehatan merupakan bagian dari pengembangan nasional yang bermaksud menaikkan kepedulian, keinginan hidup sehat bagi semua orang untuk mewujudkan harkat kesehatan masyarakat yang tinggi.

Di zaman globalisasi sekarang, sangat ramai ditemui macam-macam obat yang dijual dipasaran, mulai dari apotek, instalasi farmasi, toko obat, minimarket, sampai warung-warung pinggir jalan, yang sebagian besar tidak memiliki keilmuan dibidang farmasi. Ini tentunya mengakibatkan penyebaran obat-obatan yang makin tidak terawasi dengan baik. Padahal di dalam Undang-Undang Nomor 36 tahun 2009 tentang Kesehatan pada Pasal 98 ayat (2) menegaskan bahwa, "barang siapapun yang tidak mempunyai keilmuan dan kekuasaan dilarang memproduksi, menyimpan, menjual, dan mengedarkan obat dan bahan yang berkhasiat obat."

Menurut Siswati (2013:77), alat kesehatan semestinya harus melewati standar mutu pelayanan farmasi yang sudah ditetapkan di Peraturan Pemerintah. Pengadaan kosmetika yang tidak memiliki izin beredar ini yang pastinya kosmetik-kosmetik tersebut jelas sudah tidak aman untuk kesehatan pemakainya ini menjadikan Pemerintah gelisah dan terusik, karena kosmetik tersebut memiliki formula atau bahan-bahan terlarang yang dapat merusak kesehatan. Jadi bila ada tindak pidana di bidang kesehatan maka pasti menyerang langsung masyarakat baik secara materil maupun immaterial. Berdasarkan uraian di atas, penelitian baru ini bertujuan untuk menganalisis aturan hukum tindak pidana mengedarkan simpanan farmasi kosmetika yang tidak memiliki izin edar dan mengetahui proses implementasi sanksi bagi pelaku tindak pidana mengedarkan simpanan farmasi kosmetika yang tidak memiliki izin edr izin edar.

\section{METODE PENULISAN}

Penelitian ini menggunakan metode penelitian yuridis normative yang proses pengkajiannya melalui penelitian kepustakaan (Ibrahim, 2013). Adapun sumber bahan hukum yang digunakan yakni data primer dan data sekunder. Data primer merupakan bahan hukum mempunyai kekuatan mengikat di dalam peulisan ini meliputi, UUD NRI 1945, Udang-Undang Republik Indonesia No 36 tahun 2009 Tentang Kesehatan. Data sekunder merupakan data penunjang primer dalam hal ini adalah jurnaljurnal, buku-buku, dll. Teknik Pengumpulan Bahan Hukum yang digunakan adalah teknik kepustakaan dengan pengumpulan bahan hukum lalu dikelompokan dan didokumentasikan, dicatat, dikutip, diringkas, diulas sesuai kebutuhan dengan pendekatan kualitatif. Kemudian, teknik analisis yang digunakan adalah teknik bersifat sistematis dengan disajikan secara deskriptif-analitis, yaitu dengan mendiskripsikan bahan hukum terlebih dahulu secara sistematis kemudian menganalisa.

\section{HASIL DAN PEMBAHASAN}

\section{Pengaturan Hukum Tindak Pidana Mengedarkan Sediaan Farmasi Kosmetika yang Tidak Memiliki Izin Edar}

Kosmetik adalah unsur yang dekat dengan wanita dan dunia kecantikan. Kosmetik berawal dari kata kosmein (Yunani) yang artinya berhias. Penggunaan kosmetika mendapat sorotan yaitu selain berguna bagi kecantikan berguna juga bagi kesehatan. Ilmu tentang kosmetik lalu menyebar keberbagai penjuru dunia lewat jalur komunikasi yang terlaksana pada kegitan perdagangan, agama, budaya, politik dan militer. Di Indonesia sejarah mengenai kosmetologi diawali jauh sebelum zaman 
penjajahan Belanda. Pertumbuhan ilmu kosmetik serta industrinya baru ada secara besar-besaran pada abadke-20. Menurut Tranggono (2007:54), kosmetika ialah formula-formula yang dipakai untuk memberikan efek cantik dan sehat bagi tubuh.

Menurut Undang-undang Nomor 36 Tahun 2009 Tentang Kesehatan Pasal 1 (4) kosmetika merupakan sediaan farmasi dikarenakan pemakai kosmetika erat hubungannya dengan manusia terutama wanita, sedangkan pengertian kosmetika menurut Peraturan Menteri Kesehatan Republik Indonesia Nomor 1176/MENKES/PER/VIII/2010 adalah kosmetika merupakan formula atau campuran formula yang diaplikasiakan dengan cara dioles, ditempel, ditumpahkan, disemprotkan, atau dimasukkan ke dalam, digunakan di badan atau bagian badan manusia yang bermaksud untuk membersihkan, menjaga, menguatkan daya tarik atau mengubah rupa, dan bukan termasuk obatobatan.

Di dalam dunia kosmetika merk yang diberikan dengan harga yang lebih terjangkau hingga para penggunanya lebih berminat membelinya. Ketidaktahuan akan efek samping dari bahaya kosmetika yang tidak memiliki izin edar ini juga dapat mengakibatkan produk ini tetap banyak terjual, maka, di dalam Undang-Undang Nomor 36 Tahun 2009 diatur:

(1) Simpanan farmasi dan alat kesehatan wajib aman, memiliki khasiat atau berguna dan bernilai mutu.

(2) Barang siapa yang tidak ahli dan tidak memiliki dan wewenang tidak diizinkan mengadakan, mengemasi, memproduksi, menjual, dan menyebarluaskan obat dan bahan yang bermanfaat sebagai obat.

Pasal 106 yang menegaskan

(1) Simpanan farmasi dan alat kesehatan hanya boleh dan diizinkan beredar jika sudah mendapat izin.

Oleh sebab itu, Undang-Undang Nomor 36 Tahun 2009 akhirnya mengatur penyebarluasan simpanan farmasi di dalam Pasal 197, yaitu:

Barang siapa yang secara berencana membuat atau menjual simpanan farmasi atau alat-alat kesehatan tanpa izin edar seperti yang dimaksud di dalam Pasal 106 ayat (1) akan dijatuhkan hukuman dengan pidana penjara maksimal 15 (lima belas) tahun dan administrasi maksimal Rp1.500.000.000,00 (satu miliar lima ratus juta rupiah).

Jadi, barang siapa menyebarluaskan kosmetika atau sediaan farmasi lain yang tidak mendapat atau tanpa izin beredar dari BPOM sangat dilarang untuk menggunakan apalagi mengedarkan dengan cara apapun. Karena kosmetika yang tidak memiliki izin edar adalah kosmetika yang formula pembuatannya tidak sesuai dengan standar keamanan dan kesehatan yang diterbitkan oleh Menteri Kesehatan Republik Indonesia.

\section{Implementasi Sanksi oleh Pelaku Tindak Pidana Menyebarluaskan Simpanan Farmasi Kosmetika yang Tidak Memiliki Izin Beredar}

Sanksi Pidana merupakan satu sanksi kausa resiko kausa yaitu kasusnya dan resiko yaitu sanksinya. Pidana merupakan suatu derita yang dikenakan ke orang, derita tersebut yang dinyatakan undangundang pidana disangkutkan dengan telah terjadi pengingkaran terhadap suatu norma yang berlaku, dengan suatu putusan hakim sudah dikenakan bagi seorang yang dikatakan salah (Muladi \& Arief, 2005). Dalam penjatuhan sanksi pidana harus ada putusan hakim, dan tepat pada amar majelis hakim pertimbangan hakim adalah salah satu poin paling pentingdi dalam melihatkan terwujudnya nilai dari suatu putusan hakim yang tercantum keadilan (ex aequo et bono) dan tercantum pula kepastian hukum. Maka sanksi yang didakwakan untuk terdakwa PUTU AYU DEWI ANTAR S,Ag sesuai amar Putusan Pengadilan Negeri Denpasar Nomor Perkara 491/Pid.Sus/2018/PN DPS yaitu Pasal 197 Undang-Undang Nomor 36 Tahun 2009:

Barang siapa yang secara berencana membuat atau mengolah atau menyebarluaskan simpanan farmasi dan alat-alat kesehatan tanpa izin beredar seperti di dalam Pasal 106 ayat (1) dipidana penjara maksimal 15 (lima belas) tahun dan dikenakan administrasi maksimal Rp1.500.000.000,00 (satu miliar lima ratus juta rupiah).

Dengan pengenaan sanksi oleh Terdakwa PUTU AYU DEWI ANTARI S,Ag mempertimbangkan, sebelumnya Pengadilan mengenakan putusan harus ada hal yang dijadikan pertimbangan, yaitu hal yang menjadikan ringan dari terdakwa dan hal yang menjadikan berat terdakwa; Keadaan yang 
menjadikan berat, yaitu terdakwa sudah beberapa kali diberikan teguran oleh petugas balai besar POM Denpasar. Kemudian, Keadaan yang menjadikan ringan apabila:

a. Terdakwa telah menjaga kesopanan dan mau jujur saat persidangan

b. Terdakwa telah menyesali apa yang diperbuat

c. Terdakwa bersumpah tidak akan melakukan kembali perbuatannya.

d. Terdakwa menjadi tulang punggung keluarga

e. Terdakwa sebelumnya tidak pernah dijatuhkan hukuman apapun.

1. Menyatakan Terdakwa PUTU AYU DEWI ANTARI S.Ag telah dinyatakan secara terbukti sah dan memutuskan telah salah sudah melakukan suatu Tindak Pidana menyebarluaskan simpanan farmasi kosmetika yang tidak memiliki ijin beredar

2. Mengenakan hukuman oleh Terdakwa dengan pidana penjara selama 7 (tujuh) bulan

3. Memutuskan bahwa hukuman itu tak perlu dilakukan kecuali jika kemudian hari terdapat perintah lain di dalam amar putusan Hakim karena Terdakwa dinyatakan salah telah berbuat suatu tindap pidana atau pelanggaran sebelum waktu percobaan telah habis selama 1 (satu) tahun.

4. Mengenakan pula pidana admisnistrasi pada Terdakwa sebesar Rp. 60.000.000,00 (enam puluh juta rupiah) dengan syarat jika pidana administrasi tersebut tidak dilunasi maka harus diganti dengan pidana penjara selama 4 (empat) bulan

5. Memutuskan barang bukti berupa:
a. Temulawak Cream $=291$ kotak
b. Collagen Crystal Eye Mask $=480$ saset
Dirampas untuk dimusnahkan

\section{SIMPULAN DAN SARAN \\ 1. Simpulan}

Aturan hukum tindak pidana menyebarluaskan simpanan farmasi kosmetika tanpa izin Edar diatur di dalam Undang-Undang Nomor 36 Tahun 2009 Tentang Kesehatan Pasal 197. Siapapun yang dengan sengaja mengedarkan sediaan farmasi atau alat kesehatan yang tidak memiliki izin edar dipidana penjara paling lama 15 (Lima Belas) tahun dengan denda paling tinggi Rp. 1.500.000.000, 00 (Satu Miliar Lima Ratus Juta Rupiah). Selain itu diatur pula di dalam Peraturan Menteri Kesehatan yaitu No.1176/MENKES/PER/VIII/2010 yang menjelaskan tentang notifikasi kosmetika yaitu kosmetik merupakan formula atau bahan formula yang digunakannya dengan cara dioles, digosok atau di kulit wajah atau di tubuh manusia untuk memberikan efek kecantikan, dan meningkatkan daya Tarik tetapi kosmetika tidak bias dikatakan sebagai golongan obat. Kemudian, pengenaan sanksi pidana terhadap tindakan menyebarluaskan simpanan farmasi kosmetika tanpa izin edar oleh terdakwa Putu Ayu Dewi Antari.S,Ag adalah dipenjara selama 7 (tujuh) bulan tetapi, pidana tersebut tak perlu dilakukan karena Majelis Hakim melihat keadaan-keadaan yang meringankan dan memberatkan oleh Terdakwa oleh sebab itu pidana penjara tidak perlu dijalani oleh Terdakwa kecuali jika diesok hari ada utusan selain didalam amar putusan Hakim karena Terdakwa telah salah sudah berbuat suatu kejahatan sebelum waktu percobaan usai selama 1 (satu) tahun.

\section{Saran}

Peran Dinas Kesehatan Republik Indonesia harus lebih tegas dalam memberikan standar mutu kesehatan dan kemanfaatan bagi produsen-produsen kosmetik agar tidak lagi ada produsen kosmetik curang dalam pembuatan kosmetiknya. Selain itu peranan Badan Pengawas Obat dan Makanan harus lebih teliti dalam menjalani proses pemberian izin pada kosmetik-kosmetik yang akan dijual dipasaran, juga diharapkan selalu tepat waktu dan secara rutin mengadakan sidak untuk gerai-gerai kosmetik yang ada di daerah-daerah terutama di daerah Bali ini. Kepada masyarakat dituntut untuk lebih mau mencari informasi soal kosmetik-kosmetik yang dijual dipasaran dan diharapkan masyarakat juga lebih selektif memilih kosmetik yang akan digunakan sehingga tidak ada lagi masyarakat yang merasa dibohongi oleh pihak penjual maupun produsen kosmetik-kosmetik illegal ini. Selain itu masyarakat diajak untuk membantu pemerintah dalam pengawasan dan pengaduan.

\section{DAFTAR PUSTAKA}

DeAngelo, G., \& Gee, L. K. (2020). Peers or Police?: The Effect of Choice and Type of Monitoring in the Provision of Public Goods. Games and Economic Behavior, 123, 210-227. 
Diantara, I. K. T., Widiati, I. A. P., \& Karma, N. M. S. (2020). Penerapan Sanksi Pidana Terhadap Pelaku Tindak Pidana yang Mengedarkan Kosmetika Tanpa Izin Edar (Study Kasus Pengadilan Negeri Gianyar Nomor Pekara 132/Pid.Sus/2018 PN Gin). Jurnal Analogi Hukum, 2(2), 264-269.

Flores, D. (2016). Violence and Law Enforcement in Markets for Illegal Goods. International Review of Law and Economics, 48, 77-87.

Ibrahim, J. (2013). Teori dan Metodelogi Penelitian Hukum Normatif (7th ed.). Malang: Banyumedia Publishing.

Lane, B. R., Salmon, P. M., Desmond, D., Cherney, A., Carley, A., Hulme, A., \& Stanton, N. A. (2020). Out of Control? Using STAMP to Model the Control and Feedback Mechanisms Surrounding Identity Crime in Darknet Marketplaces. Applied Ergonomics, 89(August), 103223.

Muladi, \& Arief, B. N. (2005). Teori-teori dan Kebijakan Pidana. Bandung: Alumni.

Peng, X., Cheng, L., \& Gong, M. (2021). Measuring Public-involving Economic Crime: A Case Study in Beijing, China. International Journal of Law, Crime and Justice, 65(Juni), 1-15.

Siswati, S. (2013). Etika dan Hukum Kesehatan dalam Perspektif Undang-Undang Kesehatan. Jakarta: Rajawali Pers.

Ta'adi. (2013). Hukum Kesehatan Sanksi \& Motivasi Bagi Perawat. Jakarta: Buku Kedokteran EGC.

Tranggono. (2007). Buku Pegangan Ilmu Pengetahuan Kosmetik. Jakarta: PT.Gramedia Pustaka Utama.

Peraturan Menteri Kesehatan Republik Indonesia Nomor 1176/MENKES/PER/VIII/2010.

Undang-Undang Nomor 36 Tahun 2009 Tentang Kesehatan. 